\title{
Sensory Attributes of Cold Brew Coffee Products at Various Resting Time After Roasting Process
}

\author{
Nabiilah Salmaa Dwiranti ${ }^{1}$, Ardiansyah ${ }^{1)}$, and Nurul Asiah ${ }^{1 *}$ \\ ${ }^{1}$ Food Science and Technology Department-Universitas Bakrie, Jl. H.R. Rasuna Said Kav C-22, Kuningan, Jakarta 12920, Indonesia \\ *)Corresponding author: nurul.itpub@gmail.com \\ Received: 20 December 2018 / Accepted: 30 March 2019
}

\begin{abstract}
The quality of the brewed coffee depends on various factors. Resting time of roasted coffee beans is one of the processes that can affect the sensory characteristics of coffee brew. During resting the reduction of $\mathrm{CO}_{2}$ gas level may change and give significan effect on sensory quality of coffee. This study aims to determine the dominant sensory characteristics that can be used as quality parameters of cold brew coffee products at various resting times after roasting. The cold brew coffee product was brewed from roasted Arabica coffee beans with various resting time $(0,1,3,5,7$, and 9 days). Projective Mapping (Napping) sensory analysis method was used in this study. The samples were tested by 75 untrained panelists (naive panelists). Multiple Factor Analysis was used to obtain the cold brew coffee sample position configuration. The results of the analysis showed that panelists were able to differentiate the characteristic of sensory attributes each sample. The aroma and flavor are the main attributes that can differentiate the characteristics of each sample. From the napping method, the results obtained in the form of individual factor map and preference mapping showed that the sample resting time 1 and 3 days after roasting were assessed by the panelists as closest to the control sample (0 days). In summary, the resting time treatment of roasted coffee beans have a significant effect on the sensory characteristics of cold brew coffee products. This is proofed by changes of aroma, flavor, and aftertaste during certain period of resting time.
\end{abstract}

Keywords: Arabica coffee beans, napping, resting time, roasting, sensory

\section{INTRODUCTION}

Coffee is one of the most widely distributed drinks and mostly drunk in the world (Nadya, 2011). Coffee as strategic plantation crop, has high economic value so it acts as a source of foreign exchange, and source of income for no less than one and a half million coffee farmers in Indonesia (Rahardjo, 2012). World coffee production until July 2018 shows that Asia and Oceania at the second position below South America with a total of 48,439 ton bags $(60 \mathrm{~kg} / \mathrm{bag})$. World coffee consumption in the same year, Asia and Oceania at the second position below
Europe with a total of 35,800 ton bags (ICO, 2018).

The quality of the coffee can be seen when the coffee was brewed and served in a cup. The quality of the brewed coffee depends on the quality of the coffee beans, temperature, roasting time, resting time after roasting, water used for brewing, and brewing method. Two attributes that represent quality of coffee are aroma and flavor where it is affected by volatile and non-volatile compounds that are released by coffee when brewed (Baggenstoss et al., 2008). 
Roasting is one of the processing stages of coffee beans which greatly influences the sensory attributes of brewed coffee (Bhumiratana et al., 2011; Cheong et al., 2013; Purnamayanti et al., 2017). Not only during roasting, changes in sensory attribute characteristics are also affected when storing or resting the roasted of coffee beans (Yeretzian et al., 2012; Kreuml et al., 2013; Correa et al., 2016). Moisture content, air, and light influences the quality of the coffee beans to be brewed. The presence of air also causes the aroma in the coffee beans to become volatile (Makri et al., 2011; Toci et al., 2013).

In general, coffee was made with hot water or commonly called hot brew. However, the hot brew method has several deficiencies and health hazards, such as at temperatures $>65^{\circ} \mathrm{C}$ can cause esophageal cancer (Dirler et al., 2018) and has high acidity levels (Fuller \& Rao, 2017). Therefore, cold brew coffee product is one of solution and recently become a trend with several advantages such as has less acidic content, higher caffeine content (Fuller \& Rao, 2017), sweeter flavor, and smoother texture (Scholes, 2014).

Until now there are limited studies focuses on the sensory characteristics of cold brew coffee products, especially after resting time of roasted coffee beans. Therefore, it is necessary to do research on the sensory characteristics of coffee beverage products made by cold brewing methods after rested at different times. This research was conducted using sensory evaluation with the Projective Mapping (Napping) method to identify, describe, and quantify any characteristics for each sensory attribute of cold brew coffee products. This study aims to be able to contribute to the increase in selling value in the coffee industry, especially in Jawa Gunung Halu coffee beans which are processed by cold brew method. In addition, producers can provide information about the characteristics of the sensory attributes of cold brew coffee at various resting time of roasted coffee beans.

\section{MATERIALS AND METHODS}

Material used in this research was coffee beans Arabica Jawa Gunung Halu obtained from Cibeber, Sidangkerta Village, Mekarsari District, Bandung Regency, West Java. A total of $6 \mathrm{~kg}$ of Arabica Jawa Gunung Halu coffee beans were roasted at medium roast level.

Roasted coffee beans were given a different resting time treatment before grinding process. The resting time vary at $1,3,5,7$, and 9 days (Baggenstoss, 2008; Yeretzian et al., 2017). Based on the research of Kreuml et al. (2013) freshly roasted (roasted and brewed on the same day) can be used as a control because it has better sensory characteristics (brew-like, roasty, fruity/ aromatic, sweet) than those stored for 918 months. Different resting time treatments were given to determine the differences in sensory characteristics of cold brew coffee products. Roasted coffee beans are stored at room temperature $\left(25^{\circ} \mathrm{C}\right)$, with airtight packaging in the form of aluminum foil with zipper lock, and not allowed to be exposed to direct sunlight.

Each roasted coffee beans with difference resting time was ground with ground size 20 mesh by Latina N600 grinder. The ground beans were brewed by Hario Mizudashi Coffee Pot. The ratio of coffee powder and cold water used is 1:10 (Glowaski, 2016 with modification). Coffee powder was put into a filter tube and then poured cold water $\left(4^{\circ} \mathrm{C}\right)$ gradually until it steeps the coffee powder. Steeping results will be stored in the storage tube. Coffee powder steeped for 8 hours and stored in the refrigerator. 
Sensory evaluation was conducted by 75 untrained panelists (naive panelists) with Projective Mapping (Napping) methods (Nestrud \& Lawless, 2010). Each panelist was given $60 \times 60 \mathrm{~cm}$ white paper and six cold brew coffee samples. Panelists were asked to grouping samples based on the similarity characteristics of their sensory attributes and add a brief description of the sensory attributes of each sample. The attributes that are assessed such as the aroma, flavor, acidity, aftertaste, body, and color.

Data was analyzed by Multiple Factor Analysis (MFA) (Abdi et al., 2013) using software, R v3.4.0 with the addition of FactoMineR v1.35 packages (Husson et al., 2017) for multivariate data processing and SensoMineR v1.20 (Husson et al., 2014) for processing sensory data. This method also shows the results in the form of a colored contour map that has elevation in a dimension area or called a Preferece mapping (Prefmap) (Le \& Worch, 2014). Preference data (Pf) was obtained from the distance between each sample to the control converted by dividing the distance deviation based on the dimensions of the paper. Description data was analyzed using WordItOut online application which will show words of various sizes based on their dominant level (Miles et al., 2019).

\section{RESULTS AND DISCUSSION}

\section{Napping Configuration}

Confidence ellipses is a matrix that contains the coordinate points of the frequency and variables that replicate the number of samples based on their proximity points.

Figure 1 shows the alleged position determined by panelist with virtualization which was carried out 450 times. Based on the plot produced, the first dimension to the second dimension explains $49.74 \%$ diversity. In this dimension, 75 panelists grouped sample 214 close to 152 but in different quadrants, sample 638, 476 and 391 in the same quadrant, and sample 507 (controls) were different from the other five samples. This grouping can

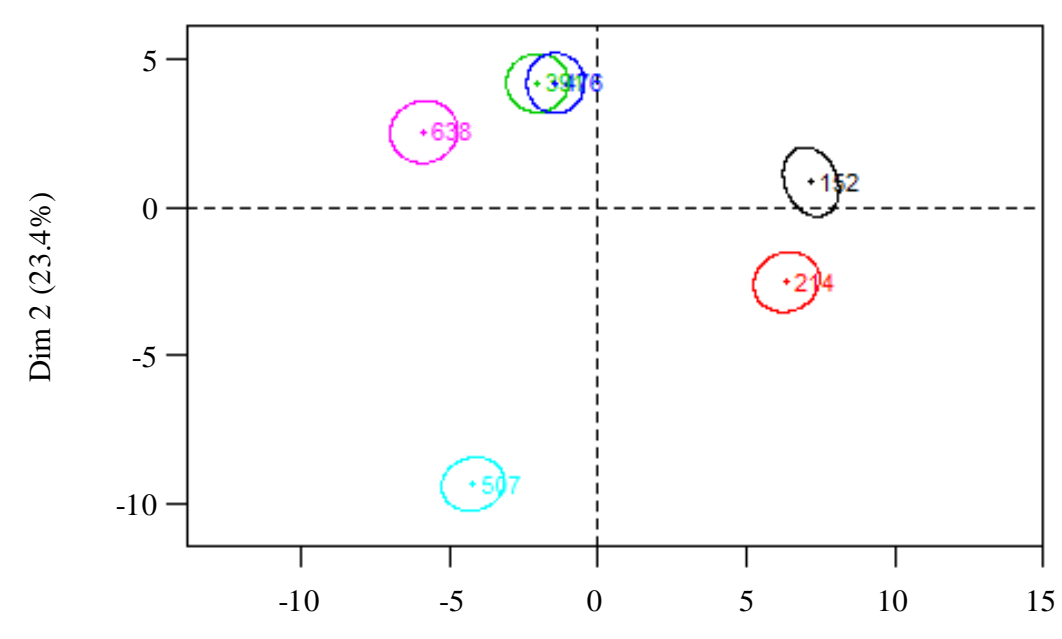

$\operatorname{Dim} 1(26.1 \%)$

Figure 1. Confidence ellipses for the napping configuration of cold brew coffee samples

Notes: $\quad 507=$ control (resting time 0 days after roasting); $214=$ resting time 1 days after roasting; $638=$ resting time 3 days after roasting; $152=$ resting time 5 days after roasting; $476=$ resting time 7 days after roasting; $391=$ resting time 9 days after roasting. 
show that the 75 panelists can differentiate the six cold brew coffee samples. This is supported by the addition of various sensory attribute characteristics descriptions for each sample.

Based on Figure 1, Table 1 and 2, sample 214 and sample 152 have some similarities in aroma attribute such as coffee, blackberry and sour aroma. In flavor attribute such a bitter, sour, and pungent. The level of acidity is medium. For aftertaste, it is bitter, sour, and tasteless. The body is liquid. However, there are differences in color, sample 214 has a dark brown color while the sample 152 has a light brown color. For sample 638, 476, and 391 also have similarities such as coffee, blackberry, sweet, and caramel for aroma attribute. In flavor attribute, there is a bitter, sour, pungent and tasteless. However, sample 638 were more acidic than the other two samples. For the acidity level and body is medium and liquid for each sample. For aftertaste is bitter, sour, and tasteless. However, the 476 sample also had a slight aftertaste. In color attribute, all three samples have a light brown color. Whereas for sample 507 (control) grouped separately from the other five samples. Besides having similar sensory descriptions like the five samples above, in the sample 507 there were some differences such as banana aroma, caramel flavor, and sweet aftertaste.

\section{Preference Mapping of Cold Brew Coffee Samples}

In Figure 2. it can be seen that the sample 214 and 391 are located at elevation $30-40^{\circ}$, sample 638 and 476 at elevation $30^{\circ}$, and

Table 1. Ctharacteristics of aroma of cold brew coffee samples

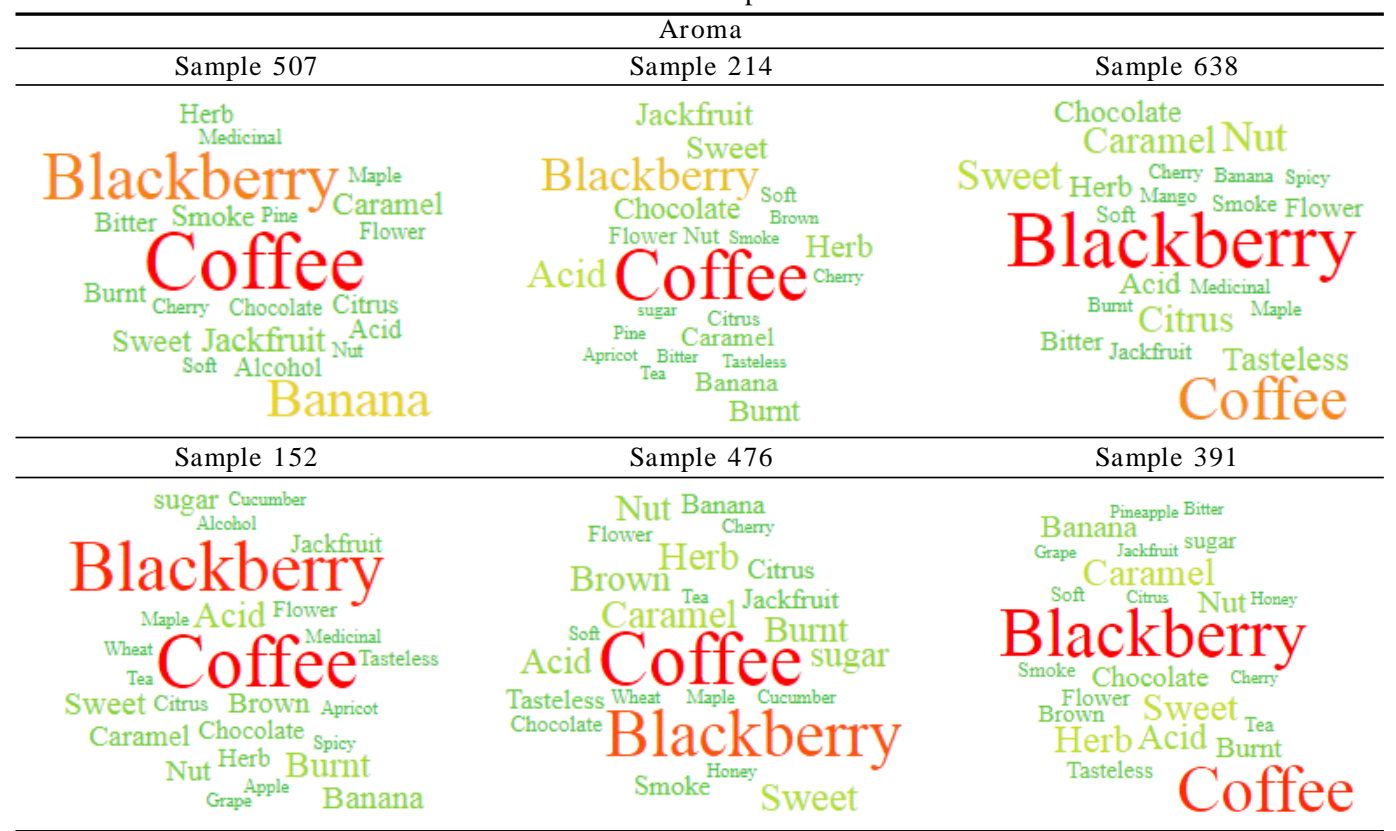

Notes: Color sequences based on dominant characteristics (Red-orange-yellow-light green-dark green) 
Table 2. Characteristics of flavor of cold brew coffee samples

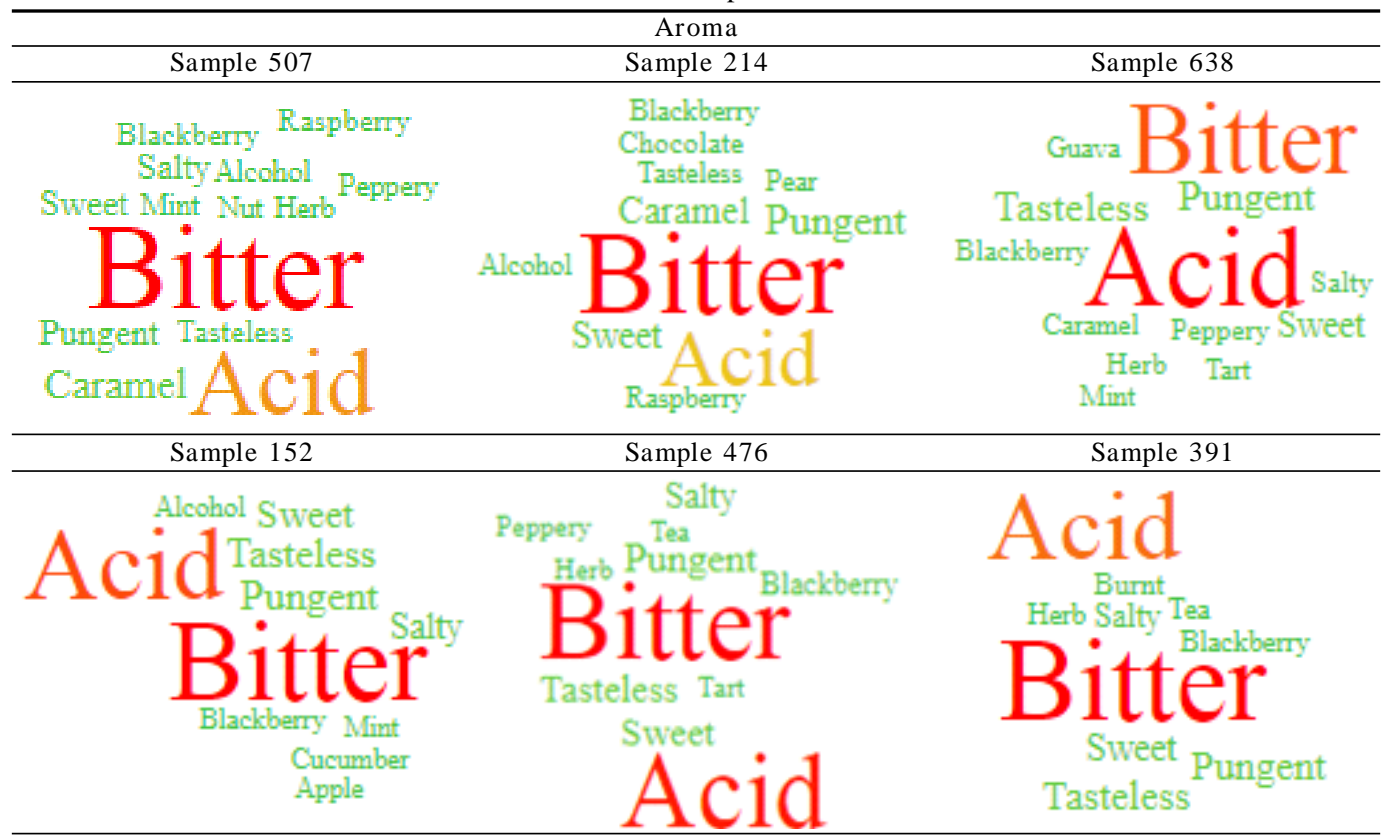

sample 152 at an elevation of $20^{\circ}$. According to the 75 panelists, samples 214 and 391 were closest to the control (sample 507) because they had the biggest elevation. Based on Table 1 and Table 2, samples 214 and 391 are closest to the control because they have similar sensory attributes such as coffee, blackberry, caramel, and sweet aroma, and bitter, sour, and slightly sweet flavor. However, sample 214 has a dark brown color that makes samples 214 and 391 at different poles.

Sample 638 and 476 had sensory attributes that were different from the control samples such as nutty aroma and also slippery and tasteless flavor. Sample 152 has a sour and burnt aroma and there is no caramel taste which makes the sample 152 located at far elevation from the control sample. While the sample 507 (control) has a coffee, blackberry, banana, jackfruit, and caramel aroma, bitter, sour, and caramel flavor, bitter, sour and sweet aftertaste, and light brown color.
These sensory characteristics are used as a reference by panelists to determine sensory characteristics of the other five samples.

\section{Aroma and Flavor}

Bitter flavor obtained from the degradation of chlorogenic acid with types 3-caffeoylquinic1,5-lactone and 4-caffeoylquinic-1,5-lactone (Farah \& Donangelo, 2006). Chlorogenic acid is an important phenolic compound in enzymatic browning reactions. This reaction can affect the flavor of coffee (Qiang \& Yaguang, 2008). Although after the roasting process most of the chlorogenic acid is damaged, roasted coffee still contains significant amounts of chlorogenic acid (Farah et al., 2005). The 1,5- $\alpha$-quinolactones compound, which was produced from chlorogenic acid during the roasting process contributes to the bitter flavor of coffee brew (Duarte \& Farah, 2008). Caffeine which is a derivative of xanthine also affects the bitter flavor of 


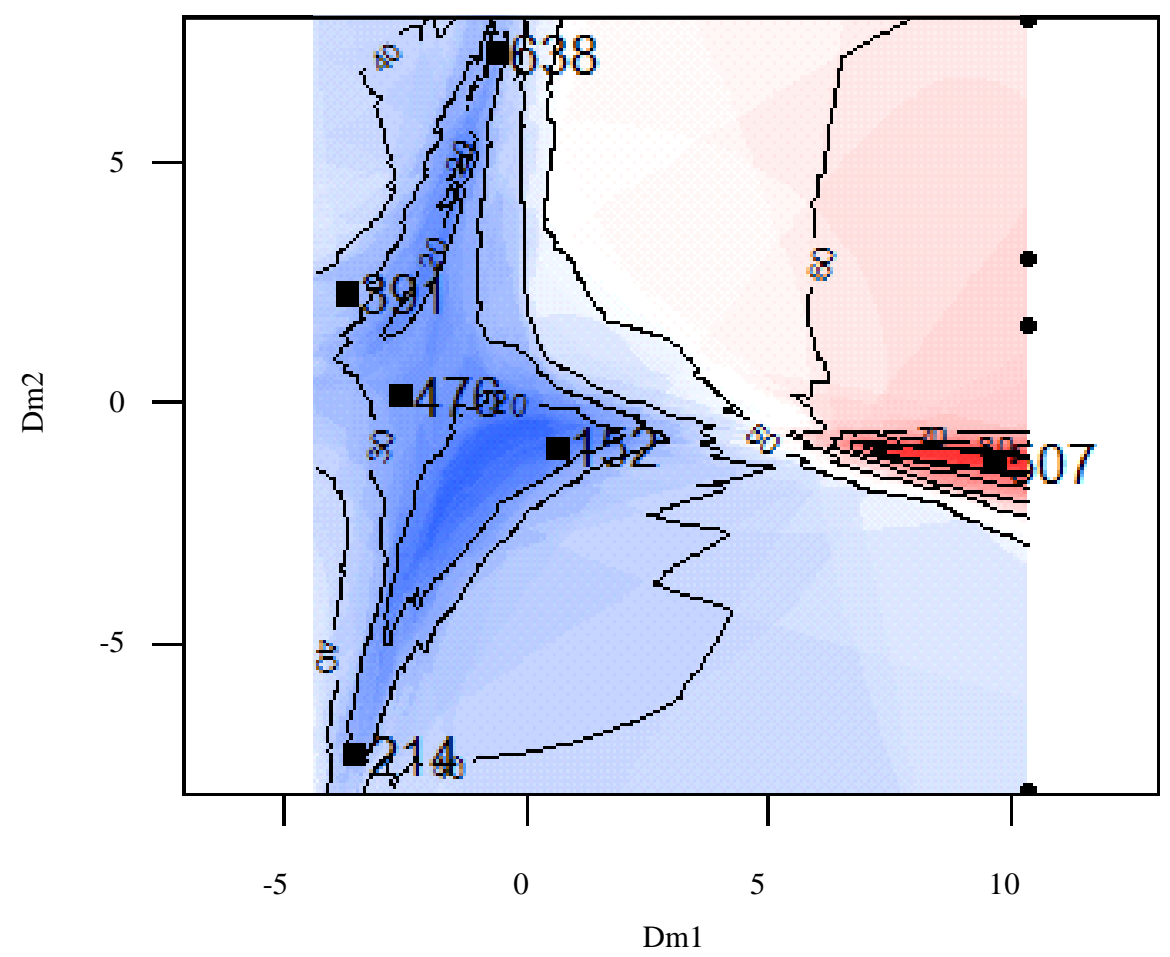

Figure 2. Preference mapping of cold brew coffee samples

coffee brew (Keast, 2008; Toci et al., 2013). Besides caffeine and chlorogenic acid, other compounds that can produce a bitter flavor in coffee brew is trigonelline. The trigonelline compounds in coffee will be degraded during the roasting process into several heterocyclic pyridine components which give the aroma of roasted coffee. However, incompletely degraded trigonelline causes a bitter flavor for the coffee. The trigonelline content in Arabica beans is $0.6-1.3 \%$ (Panggabean, 2011). Two compounds due to thermal decomposition of trigonelline are $\mathrm{N}$-methylpyridinium and nicotinic acid. The two compounds continued to increase during roasting but decreased by $60-90 \%$ within seven minutes after the roasting process (Wei \& Tanokura, 2015).

The acid flavor detected in coffee brew comes from the acid content in coffee beans such as from the carboxylic acid group including formic acid, acetic acid, oxalic acid, citric acid, lactic acid, malic acid, and quinic acid (Widyotomo et al., 2009). During the fermentation and roasting process, it will affect the level of acidity in the coffee brew. The sour and bitter flavor of coffee produced from breakdown of chlorogenic acid into quinic acid and caffeic acid through the process of esterification during roasting (Clifford, 2000). These acidic compounds can be produced through the shikimic acid pathway.

Sweet and caramel flavor and aroma were produced from total sugar and nonreducing sugars in coffee (Partelli et al., 2012). The sweet flavor in coffee is also produced from the Maillard reaction that takes place during the roasting process. Apart from the roasting process, sweetness in cold brew coffee was produced because cold water cannot degrade and oxidize the 
oil content in the coffee so that it does not cause sour and bitter flavor in the coffee brew.

This research also obtained several other flavors and aromas such as the flavor and aroma of fruit and flowers produced from aldehyde compounds, namely acetaldehyde and propanal (Wang, 2012). This compound was produced from sugar pyrolysis. Other aldehyde compounds such as 2-methylpropanal, 2-methylbutanal, and 3-methylbutanal are Strecker's degradation products of valine, isoleucine, and leucine (Liardon et al., 1984). Furan compounds produce sweet, fruit, floral, earthy-like, caramel, peanut, smoke, and roasted-like aroma. Pyrazine compounds produce a coffee, nutty, roasted-like, and earthy-like aroma. These compounds were formed from complex interactions between $\alpha$-amino acids and carbohydrates. Alkyl pyrazine such as 2-ethyl-5-methylpyrazine can produce a coffee and nutty aroma (Wang, 2012). Phenol compounds produce smoke, pungent, clove, bitter, and pungent aroma. Pyrrole compounds produce coffee, flowers, and smoke aroma were produced from the degradation of amino acids and amadori intermediates (Flament, 2002). Ketones such as (E) - $\beta$-damascenone have a honey, fruit, sweet, and tea flavor (Poltronieri \& Rossi, 2016). Other compounds that often appear are methional, 3-hydroxy-4,5-dimethyl2-(5H)-furanone, vanillin, and 4-vinyl- and 4-ethylguaiacol (with pungent, smoke, and sweet flavor) (Belitz et al., 2009).

Overall, the resting time treatment of roasted coffee beans can have a significant effect on the sensory characteristics of cold brew coffee samples. This can be seen from the reduction or addition of sensory characteristics to the aroma, flavor, and aftertaste attribute and also the grouping of the six samples based on various resting time treatments.

\section{CONCLUSIONS}

It can be conclude that sensory attributes of cold brew coffee products differ at various resting time. The longer resting time followed by significant sensory characteristics changes of flavor and aroma. The panelist migh identifiead flavors and aromas as spices, nutty, sweet, floral, fruity, roasted and other. Where each attribute has a wide variety. The fruity flavor can be descripe with specific flavor, such as blackbery, banana, cherry, grap, citrus etc. But still there are dominant aroma and flavor attributes that do not change significantly. The dominant aroma of Arabica Jawa Gunung Halu coffee are coffee aroma and blackbery aroma and the dominant flavor are bitter and acid.

\section{REFERENCES}

Abdi, H.; L.J. Williams \& D. Valentin (2013). Multiple Factor Analysis: Principal Component Analysis for Multitable and Multiblock Data Sets. WIREs Comput Stat. Willey Periodicals, Inc.

Baggenstoss, J. (2008). Coffee Roasting and Quenching Technology - Formation and Stability of Aroma Compounds. Doctoral thesis. ETH Zurich, German.

Baggenstoss, J.; L. Poisson; R. Kaegi; R. Perren $\&$ F. Escher (2008). Coffee roasting and aroma formation: Application of different time-temperature conditions. Journal of Agricultural and Food Chemistry, 56, 5836-5846.

Belitz, H.D.; W. Grosch \& P. Schieberle (2009). Food Chemistry. Springer, Berlin.

Bhumiratana, N.; K. Adhikari \& E. Chambers (2011). Evolution of sensory aroma attributes from coffee beans to brewed coffee. LWT-Food Science and Technology, 44, 2185-2192. 
Cheong, M.W.; K.H. Tong; J.J.M. Ong; S.Q. Liu; P. Curran \& B. Yu (2013). Volatile composition and antioxidant capacity of Arabica coffee. Food Research International Journal, 388-396.

Clifford, M.N. (2000). Chlorogenic acids and other cinnamates nature, occurrence, dietary burden, absorption and metabolism. Journal of Science Food Agriculture, 80, 1033-1043.

Correa, P.C.; G.H.H. Oliveira; A.P.L.R. Oliveira; G.A. Vargas-Elias; F.L. Santos \& F.M. Baptestini (2016). Preservation of roasted and ground coffee during storage Part 1: Moisture content and repose angle. Revista Brasileira de Engenharia Agricola e Ambiental, 20, 581-587.

Dirler, J.; G. Winkler \& D.W. Lachenmeier (2018). What temperature of coffee exceeds the pain threshold? Pilot study of a sensory analysis method as basis for cancer risk assessment. Foods, 7, 1-12.

Duarte, G. \& A. Farah (2008). Chlorogenic acids and lactones on Brazilian commercial coffees. Proceedings $22^{\text {nd }}$ International Conference on Coffee Science (ASIC), p. 224-227. Campinas, Brazil.

Farah, A.; T. De Paulis; L.C. Trugo \& P.R. Martin (2005). Effect of roasting on the formation of chlorogenic acid lactones in coffee. Journal of Agricultural and Food Chemistry, 53, 1505-1513.

Farah, A. \& C.M. Donangelo (2006). Phenolic compounds in coffee. Brazilian Journal of Plant Physiology.

Flament, I. (2002). The individual constituents: structure, nomenclature, origin, chemical and organoleptic properties. p. 81-335. In: Coffee Flavor Chemistry, Wiley. Chichester, U.K.

Fuller, M. \& N.Z. Rao (2017). The effect of time, roasting temperature, and grind size on cafeine and chlorogenic acid concentrations in cold brew coffee. Scientific Report, 7, 17979.
Glowaski, T. (2016). How to brew cold coffee with the hario cold brewer-aka-the mizudashi. https://questcoffee.com.au/ how-to-brew-cold-coffee-with-thehario-cold-brewer-aka-the-mizudashi/. Accessed on date February $23^{\text {rd }} 2018$.

Husson, F.; S. Le \& M. Cadoret (2014). SensoMineR: Sensory data analysis with R. R package version 1.20. http://www.CRAN. Rproject.org/package=SensoMineR. Accessed on date February $15^{\text {th }} 2018$.

Husson, F.; J. Josse.; S. Le \& J. Mazet (2017). FactoMineR: Multivariate exploratory data analysis and data mining with $\mathrm{R}$. $\mathrm{R}$ package version 1.35. CRAN.RProject. FactoMineR.

ICO (2018). Coffee Market Report. International Coffee Organization.

Keast, R.S.J. (2008). Modification of the bitterness of caffeine. Food Quality, 19, 465-472.

Kreuml, M.T.L.; D. Majchrzak; B. Ploederl \& J. Koenig (2013). Changes in sensory quality characteristics of coffee during storage. Food Science and Nutrition Journal, 1, 267-272.

Le, S. \& T. Worch (2014). The R Series: Analyzing Sensory Data with R. Taylor and Francis Group. CRC Press. New York.

Liardon, R.; U. Ott \& N. Daget (1984). Analysis of coffee headspace profiles by multivariate statistics. p. 447-459. In: P. Schreier (Ed). Analysis Volatiles: Methods and Applications. Walter de Gruyter \& Co. Berlin, New York.

Makri, E.; D. Tsimogiannis; E.K. Dermesonluoglu \& P.S. Taoukis (2011). Modeling of Greek coffee aroma loss during storage at different temperatures and water activities. Procedia Food Science, 1, 1111-1117.

Miles, M.B.; A.M. Huberman \& J. Saldana (2019). Qualitative Data Analysis: A Methods Sourcebook. $5^{\text {th }}$ Edition. Sage Publications. United State. 
Nadya, S. (2011). 1001 Fakta Tentang Kopi. Penerbit Cahaya Atma Pustaka. Yogyakarta.

Nestrud, M.A. \& H.T. Lawless (2010). Perceptual mapping of apples and chesses using projective mapping and sorting. Journal of Sensory Studies, 25, 309-324.

Panggabean, E. (2011). Buku Pintar Kopi. AgroMedia Pustaka. Jakarta.

Partelli, F.L.; O. Partelli; A.S. Partelli; F.M. Borem; J.H.S. Taveira; R.S.R. Pinto \& V.C. Siqueira (2012). Quality of conilon coffee dried on a concrete terrace in a greenhouse with early hulling. In: Proceedings $24^{\text {th }}$ International Conference on Coffee Science (ASIC). p. 465-468. Costarica.

Poltronieri, P. \& F. Rossi (2016). Challenges in specialty coffee processing and quality assurance. Challenges, 7, 1-22.

Purnamayanti, N.P.A.; I.B.P. Gunadnya \& G. Arda (2017). Pengaruh suhu dan lama penyangraian terhadap karakteristik fisik dan mutu sensori kopi Arabika. Jurnal Biosistem dan Teknik Pertanian, 5, 39-48.

Qiang, H. \& L. Yaguang (2008). Elucidation of the mechanism of enzymatic browning inhibition by sodium chlorite. Food Chemistry, 110, 847-885.

Rahardjo, P. (2012). Panduan Budidaya dan Pengolahan Kopi Arabika dan Robusta. Penebar Swadaya. Jakarta.

Scholes, C.A. (2014). The perfect roast reaction. p. 13-15. In: Chemistry in Australia: Coffee Beans and the Perfect Brew. Royal Australian Chemical Institute. Australia.
Sukiman, S. (2015). What roasting dates can \& can't tell you about coffee. https:// www.perfectdailygrind.com/2015/09/ what-roasting-dates-can-cant-tell-youabout-coffee/. Accessed on date March $10^{\text {th }} 2018$.

Toci, A.T.; V.J.F.M. Neto; A.G. Torres; V. Calado \& A. Farah (2008). Triacylglicerols changes during the storage of roasted coffee. In: Proceedings $22^{\text {nd }}$ International Conference on Coffee Science (ASIC). p. 504-507. Campinas, Brazil.

Toci, A.T.; V.J.M.F. Neto.; A.G. Torres \& A. Farah (2013). Changes in triacylglycerols and free fatty acids composition during storage of roasted coffee. LWT - Food Science and Technology, 50, 581-590.

Wang, N. (2012). Physicochemical Changes of Coffee Beans during Roasting. Ontario (CA): The University of Guelph, thesis.

Wei, F. \& M. Tanokura (2015). Chemical changes in the components of coffee beans during roasting. Coffee in Health and Disease Prevention, Chapter 10, 83-91.

Widyotomo, S.; S. Mulato; H.K. Purwadaria \& A.M. Syarief (2009). Karakteristik proses dekafeinasi kopi Robusta dan reaktor kolom tunggal dengan pelarut etil asetat. Pelita Perkebunan, 25, 101-125.

Worditout.com. (2018). https://worditout.com/ Accessed on date July $10^{\text {th }} 2018$.

Yeretzian, C.; I. Blank \& Y. Wyser (2017). Protecting the flowers - Freshness as a key to quality. p. 329-353. In: The Craft and Science of Coffee. Academic Press, United States.

$$
* * 0 * *
$$

